\title{
Диагностика изменений микроструктуры поверхности и объема сульфокатионообменной мембраны МК-40 при электродиализе сильноминерализированных природных вод
}

\author{
Яцев А.М., Акберова Э.М., Голева Е.А., Васильева В.И., Малыхин М.Д. \\ ФГБОУ ВО «Воронежский государственный университет», Воронеж
}

Поступила в редакцию 31.01.2017 г.

Проведена оценка структурных изменений материала катионообменной мембраны МК-40 после длительной эксплуатации в электродиализаторе реверсного типа. Установлено влияние морфологических изменений и образования осадков после электродиализа природных вод на физикохимические и электрохимические свойства мембраны. Установлено ухудшение транспортных свойств мембраны вследствие осадкообразования, затрагивающего не только поверхность, но и ее объем.

Ключевые слова: катионообменная мембрана, реверсный электродиализатор, природные воды.

\section{Diagnosis of surface and bulk microstructure changes of the MK-40 sulfocation exchange membrane at electrodialysis of highly mineralized natural waters}

\author{
Yatsev A.M., Akberova E.M., Goleva E.A., Vasil’eva V.I., Malykhin M.D. \\ Voronezh State University, Voronezh
}

An important limitation which worsens efficiency of electrodialysis during natural waters demineralization is to reduce of the membrane electrochemical activity under the influence of polarization and temperature effects as well as salt fouling. The purpose of this work is the detection of the relationship between the structural and transport properties of MK-40 sulfocation exchange membrane after prolonged use in the reverse electrodialysis stack during desalination of natural waters.

Structural changes of the MK-40 cation exchange membrane material after continuous operation in the reverse electrodialysis stack are evaluated by the scanning electron microscopy. The physicochemical characteristics of membranes were identified by the standard procedures. The conductivity was measured by the contact-difference method. The diffusion properties of membranes were determined by estimating the amount of electrolyte, which was transported through the membrane to the water.

The influence of the morphological changes and scaling after electrodialysis of natural waters on the electrochemical and physicochemical properties of the MK-40 cation exchange membrane is established. Possible reasons of deterioration of membrane operational properties at the process of demineralization of natural water by electrodialysis are revealed. The degradation of the membrane transport properties as a result of scaling, affecting not only the surface but also the bulk of the membrane, is established. Formation of slightly soluble compounds leads to blocking of functional groups and transport channels of the membrane, decreasing of selectivity and electrical conductivity, and hindering of the diffusion processes.

Keywords: cation exchange membrane, reverse electrodialysis, natural waters. 


\section{Введение}

Важным ограничением, ухудшающим эффективность электродиализа при деминерализации природных вод, является снижение электрохимической активности мембран под воздействием поляризационных и температурных эффектов, а также осадкообразования [1]. Выпадение в осадок на поверхности и в объеме мембран кристаллических неорганических соединений, таких как труднорастворимые соли и гидроксиды, значительно ухудшает их эксплуатационные характеристики при опреснении вод с высоким значением жесткости [2-7]. Образовавшиеся осадки уменьшают рабочую поверхность мембраны, увеличивают электросопротивление аппарата, снижают выход по току и делают невозможным дальнейшее протекание процесса. В связи с этим приходится ограничивать рабочую величину плотности тока, что негативно сказывается на производительности.

Для предотвращения образования осадков на мембранах обычно используют метод катионообменного умягчения воды и прием переполюсовки электродов с одновременным изменением потоков дилюата и концентрата при электродиализе (реверсный электродиализ). При таком переключении происходит изменение функций камер: камеры концентрирования переходят в камеры обессоливания и наоборот, а образовавшийся осадок растворяется $[8,9]$. Недостаток - увеличение затрат на изготовление обоих электродов из благородных металлов, например платины.

Проведение электродиализа в импульсном режиме также способствует предотвращению осадкообразования на мембранах $[10,11]$, т.к. в этом случае предельная плотность тока достигается при больших значениях, по сравнению со стационарным режимом. Отличие импульсного режима от стационарного заключается в варьировании формы, амплитуды и частоты тока (потенциала), которые позволяют регулировать $\mathrm{pH}$ примембранного слоя, тем самым влияя на процесс осадкообразования на мембранах [12]. Однако жесткие условия эксплуатации снижают эффективность процесса из-за изменения структурных и транспортных свойств мембран [13].

Физико-химические свойства и эксплуатационные качества ионообменных мембран находятся в непосредственной связи с их структурой. Влияние воздействия тока и температуры в ходе электродиализа на электрохимические и структурные свойства, приводящее к необратимым изменениям в мембранах, отмечалось в [1421]. Цель настоящей работы - выявление взаимосвязи между структурными и транспортными характеристиками сульфокатионообменной мембраны МК-40 после длительной эксплуатации в электродиализаторе реверсного типа при обессоливании природных вод.

\section{Эксперимент}

В качестве объекта исследования был выбран образец выпускаемой ООО ИП «Щекиноазот» гетерогенной сульфокатионообменной мембраны МК-40, проработавшей в электродиализаторе реверсного типа при обессоливании природных вод. Мембрану МК-40 изготавливают методом горячего прессования, она состоит из сильнокислотного ионита КУ-2 (65\%) с сульфогруппами в качестве ионогенных групп, полиэтилена и армирующей ткани капрона. Доля инертных участков (полиэтилен), снижающих величину активной поверхности массопереноса, достигает 0.85 [22]. Мембрана была извлечена после 1000 часов работы из приэлектродной секции реверсного электродиализного аппарата, схема которого показана на рис. 1.

Известно [16], что мембраны, расположенные в электродных секциях, работают в наиболее жестких условиях, поскольку в этом случае мембрана непосредст- 
венно соприкасается с продуктами, образующимися при электролизе минерализованной воды и растворов электролита. На отрицательно заряженном катоде продуктами электролиза являются водород и гидроксид-ионы (1), а на положительно заряженном аноде выделяются кислород и ионы водорода (2):

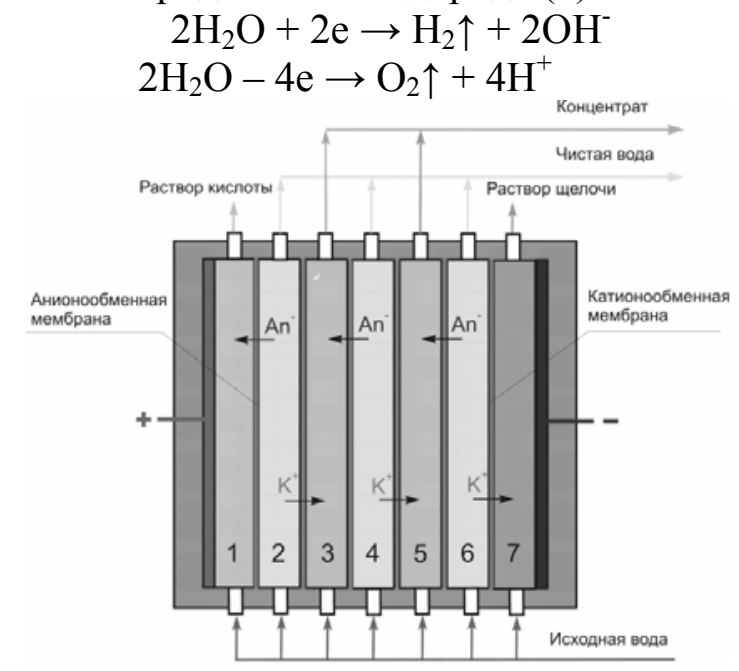

Рис.1. Схема установки реверсного аппарата-электродиализатора

Химический состав природных вод Аральского региона с высоким значением жесткости и большим количеством хлоридов и сульфатов представлен в табл. 1.

Таблица 1. Химический состав вод Аральского региона

\begin{tabular}{|c|c|c|}
\hline Компонент & мг/дм ${ }^{3}$ & ммоль/дм ${ }^{3}$ \\
\hline Натрий & 3911 & 170.0 \\
\hline Калий & 23 & 0.6 \\
\hline Кальций & 313 & 7.8 \\
\hline Магний & 400 & 16.7 \\
\hline Гидрокарбонаты & 183 & 3.0 \\
\hline Сульфаты & 1368 & 14.2 \\
\hline Хлориды & 6671 & 188.0 \\
\hline Общее солесодержание & 12870 & \\
\hline Жесткость, мг-экв/дм ${ }^{3}$ & \multicolumn{2}{|c|}{49} \\
\hline $\mathrm{pH}$ & \multicolumn{2}{|c|}{7.5} \\
\hline
\end{tabular}

Физико-химические, транспортные и структурные характеристики мембран после эксплуатации сравнивали с образцами мембраны МК-40, кондиционированными по стандартным методикам [23].

Интегральный коэффициент диффузионной проницаемости мембран определяли методом оценки количества электролита, перенесенного из раствора соли заданной концентрации под влиянием диффузионных сил через исследуемую мембрану в чистую воду [24]. Для измерения удельной электропроводности был применен контактно-разностный метод [25], заключающийся в измерении импедансов одной и двух мембран в ячейке с платиновыми электродами и нахождении их векторной разности, которую рассматривали как истинное электросопротивление мембраны.

Морфологию поверхности сухих и набухших образцов мембран исследовали методом растровой электронной микроскопии (РЭМ) на приборе JSM-6380 LV (Япония), оснащенном энергодисперсионным анализатором элементного состава и регулятором давления в камере с исследуемым образцом. 


\section{Обсуждение результатов}

Сравнение основных физико-химических характеристик образцов сульфокатионообменной мембраны МК-40 после химического кондиционирования и эксплуатации в реверсном электродиализаторе представлено в табл. 2. Установлено, что уменьшение полной обменной емкости мембран сопровождается уменьшением влагосодержания и ростом толщины.

Таблица 2. Физико-химические характеристики набухших образцов сульфокатионообменной мембраны МК-40 после кондиционирования и работы в реверсном электродиализаторе

\begin{tabular}{|c|c|c|c|c|}
\hline Образец мембраны & $\begin{array}{c}\mathrm{Q}, \\
\text { ммоль/Г }\end{array}$ & $\begin{array}{c}\text { Влагосодержание } \\
\mathrm{W}, \%\end{array}$ & $\begin{array}{c}\text { Толщина, } \\
\text { мкм }\end{array}$ & $\begin{array}{c}\text { Плотность, } \\
\text { г/см }\end{array}$ \\
\hline Кондиционированный & $1.52 \pm 0.08$ & $33 \pm 1$ & $520 \pm 10$ & 1.19 \\
\hline $\begin{array}{c}\text { Из аппарата- } \\
\text { электродиализатора }\end{array}$ & $1.29 \pm 0.06$ & $31 \pm 1$ & $560 \pm 5$ & 1.19 \\
\hline
\end{tabular}

Исследование транспортных характеристик мембран МК-40 показало, что по сравнению с кондиционированным образцом длительная эксплуатация привела к уменьшению удельной электропроводности в 1.4 раза (рис. 2) и диффузионной проницаемости в 1.2 раза (рис. 3). Данный факт обусловлен тем, что в процессе длительной эксплуатации этих образцов мембран произошла не только деструкция ионогенных групп вследствие воздействия продуктов электролиза и перегрева, а также значительные изменения микроструктуры их поверхности и объема, связанные с образованием минеральных отложений. При электродиализном опреснении природных соленых и солоноватых вод образующиеся на поверхности мембран осадки состоят в основном из карбоната кальция, сульфата кальция и гидроксида магния (табл. 3).

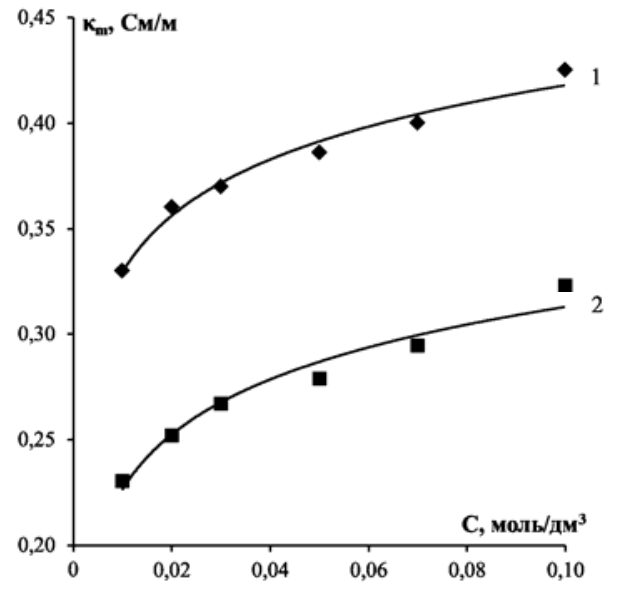

Рис.2. Концентрационные зависимости удельной электропроводности кондиционированного (1) образца мембраны МК-40 и из приэлектродной секции реверсного электродиализного аппарата (2)

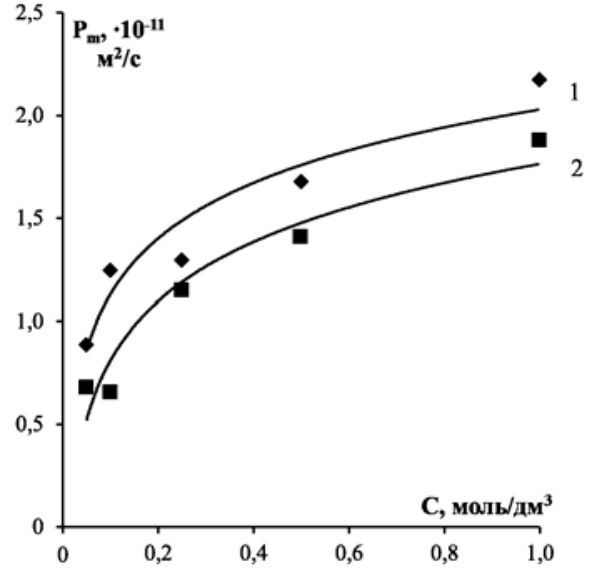

Рис.3. Концентрационные зависимости диффузионной проницаемости кондиционированного (1) образца мембраны МК-40 и из приэлектродной секции реверсного электродиализного аппарата (2)

Образование осадков карбоната кальция $\left(K_{S}=4.8 \cdot 10^{-9}\right)$ и гидроксида магния $\left(K_{S}=1.8 \cdot 10^{-11}\right)$ является следствием увеличения $\mathrm{pH}$ растворов при превышении предельной диффузионной плотности тока. Меньшие потоки водородных ионов через катионообменные мембраны по сравнению с потоками гидроксильных ионов через анионообменные мембраны приводят при деминерализации воды к увеличению $\mathrm{pH}$ 
раствора в секциях концентрирования и созданию в них условий для образования осадков. В этом случае у отдающей поверхности анионообменной мембраны и у принимающей поверхности катионообменной мембраны происходит подщелачивание раствора [27]. При увеличении рН обрабатываемых растворов возможно также осаждение малорастворимых гидроксидов или карбонатов вследствие нарушения углекислотного равновесия в системе [28]. Изменение $\mathrm{pH}$ растворов не оказывает заметного влияния на процесс образования сульфата кальция $\left(K_{S}=9.1 \cdot 10^{-6}\right)$, обусловленного достижением и превышением предела его растворимости.

Таблица 3. Состав предполагаемых нерастворимых соединений, образующихся на поверхности и в объеме мембраны, и их константы растворимости

\begin{tabular}{|c|c|}
\hline Предполагаемый осадок & Константа растворимости $\mathrm{K}_{\mathrm{s}}[26]$ \\
\hline $\mathrm{CaCO}_{3}$ & $4.8 \cdot 10^{-9}$ \\
\hline $\mathrm{CaSO}_{4}$ & $9.1 \cdot 10^{-6}$ \\
\hline $\mathrm{MgCO}_{3}$ & $2.1 \cdot 10^{-5}$ \\
\hline $\mathrm{Mg}(\mathrm{OH})_{2}$ & $1.8 \cdot 10^{-11}$ \\
\hline $\mathrm{Fe}(\mathrm{OH})_{3}$ & $3.2 \cdot 10^{-38}$ \\
\hline
\end{tabular}

Электронно-микроскопические изображения поверхности образца мембраны МК-40 из приэлектродной секции реверсного электродиализатора представлены на рис. 4. Визуально можно наблюдать образование прочно скрепленного с поверхностью мембраны осадка, локализованного не только в областях с хорошей электропроводностью, где находятся частицы ионообменника, но и покрывающего сплошной пленкой практически всю поверхность мембран.

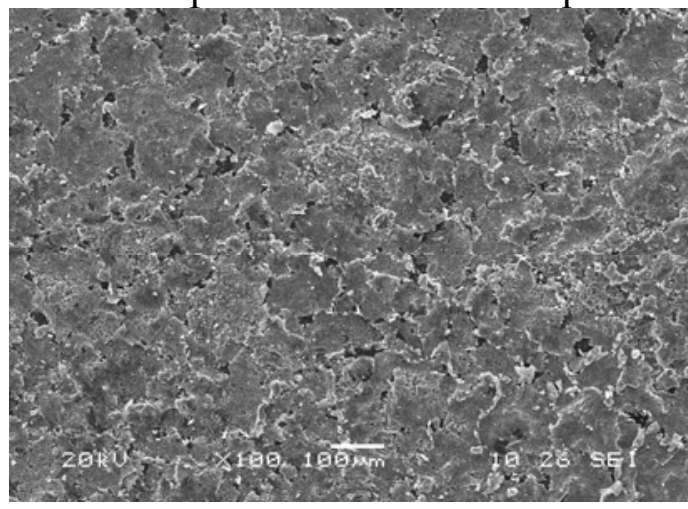

a

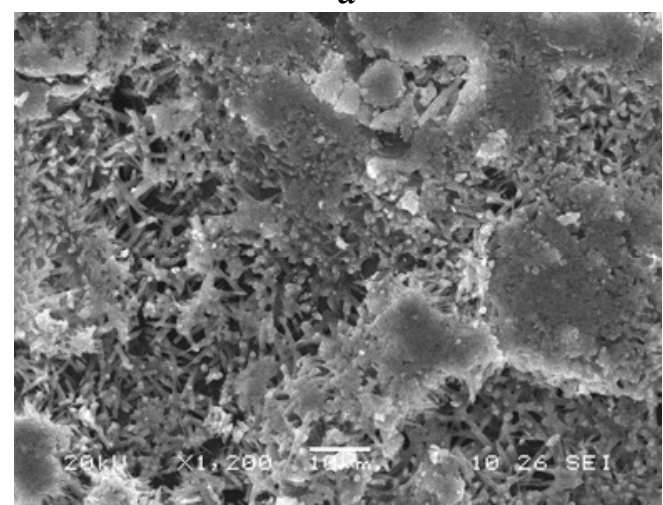

B

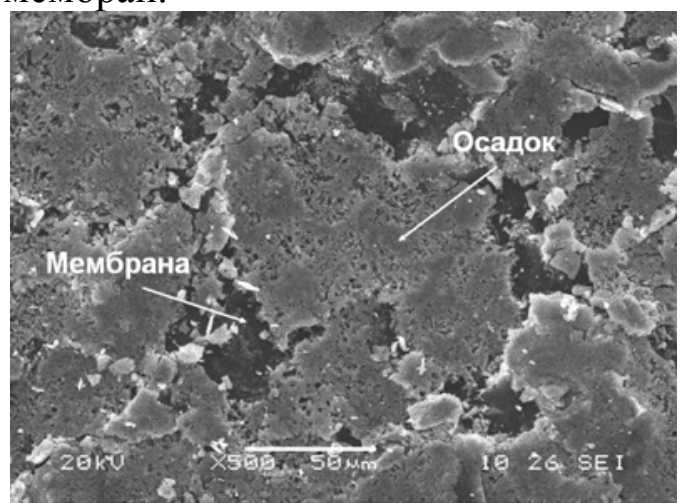

6

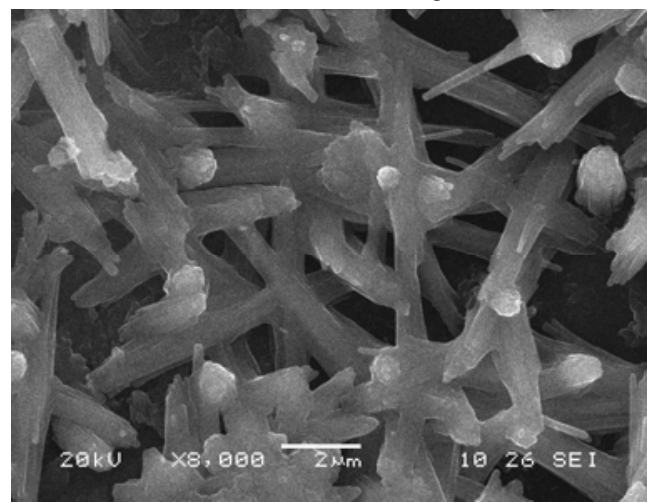

$\Gamma$

Рис. 4. РЭМ-изображения поверхности сухого образца мембраны МК-40 из приэлектродной секции реверсного электродиализатора при увеличении 100 (a), 500 (б), 1200 (в), 8000 (г) 
Композитные рентгеновские карты распределения элементов Са (серый цвет) и $\mathrm{Mg}$ (черный цвет) по поверхности катионообменной мембраны МК-40 (рис.5) и результаты рентгеноспектрального микроанализа компонентного состава пленки осадка (табл. 4) показали преимущественное содержание Са (16.17 мас. \%) и присутствие элементов $\mathrm{Mg}(1.25$ мас. \%), Fe (1.28 мас. \%), Si (0.05 мас. \%).

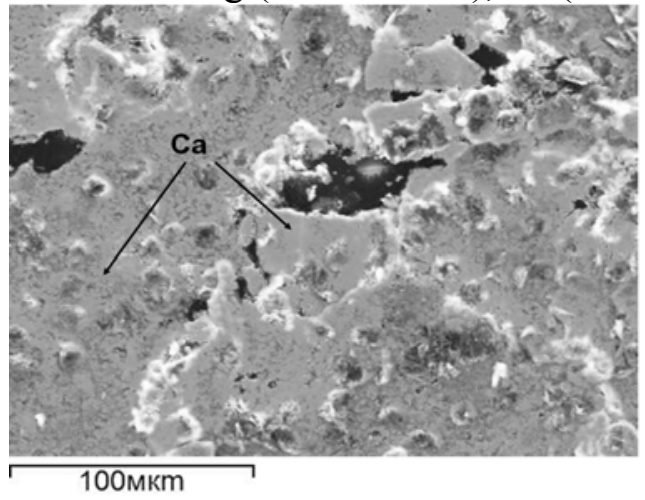

a

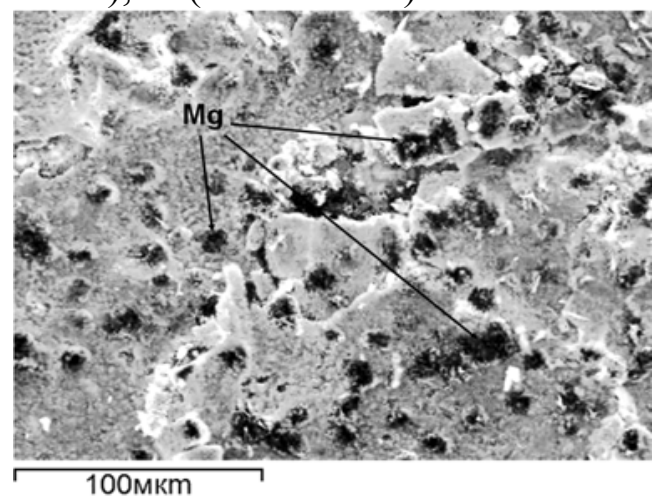

6

Рис. 5. Композитные рентгеновские карты распределения Са (а, серый цвет) и $\mathrm{Mg}$ (б, черный цвет) по поверхности катионообменной мембраны МК-40 из приэлектродной секций реверсного электродиализатора (увеличение 500)

Таблица 4. Элементный состав поверхности и среза мембраны МК-40 кондиционированной и извлеченной из приэлектродной секции реверсного электродиализатора

\begin{tabular}{|c|c|c|c|c|}
\hline \multirow{3}{*}{ Элемент } & \multicolumn{4}{|c|}{ Концентрация, мас. \% } \\
\cline { 2 - 5 } & \multicolumn{4}{|c|}{ Образецембраны МК-40 } \\
\cline { 2 - 5 } & Пондиционированный & Из аппарата-электродиализатора \\
\hline $\mathrm{C}$ & Поверхность & Срез & Поверхность & Срез \\
$\mathrm{O}$ & 51.05 & 80.15 & 38.15 & 57.38 \\
$\mathrm{~S}$ & 5.58 & 13.89 & 40.10 & 28.99 \\
$\mathrm{Ca}$ & 2.96 & - & 0.70 & 2.25 \\
$\mathrm{Mg}$ & - & - & 16.17 & 1.18 \\
$\mathrm{Fe}$ & - & - & 1.25 & 8.34 \\
$\mathrm{Si}$ & - & - & 1.28 & 0.91 \\
\hline
\end{tabular}

В соответствии с составом очищаемой воды Аральского региона, содержащей ионы $\mathrm{Ca}^{2+}, \mathrm{Mg}^{2+}, \mathrm{SO}_{4}^{2-}, \mathrm{HCO}_{3}^{-}$у поверхности мембраны может быть превышена константа растворимости, и наиболее вероятно образование осадков сульфата кальция и карбонатов кальция и магния. Форма изображенных на рис. 4г кристаллов соответствует характерным кристаллам гипса $\mathrm{CaSO}_{4}$. Однако известно [5], что образование рыхлого осадка $\mathrm{CaSO}_{4}$ не влияет на электрохимические свойства мембран, в отличие от плотного осадка $\mathrm{CaCO}_{3}$. Различное влияние осадков карбонатов и сульфатов на электрохимические характеристики мембран авторами [5] объясняется слабой адгезией сульфата кальция к поверхности ионообменной мембраны. При концентрации гидрокарбонат-ионов в деминерализируемой подземной воде 183 мг/дм³ осаждение карбоната кальция должно начинаться уже при незначительном превышении $\mathrm{pH}$ исходной воды.

Выявлено, что осадкообразование затрагивает не только поверхность, но и объем мембраны. Сопоставление данных об элементном составе среза (табл. 4) и композитные рентгеновские карты распределения элементов (рис. 6) позволяет сде- 
лать вывод о различном содержании и различной локализации осадка по площади сечения.

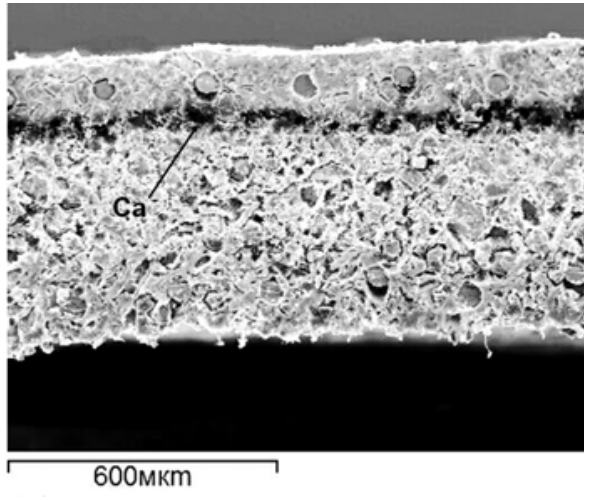

a

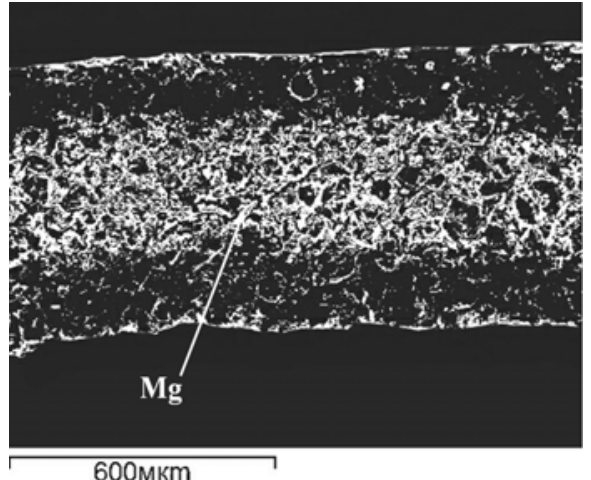

6

Рис. 6. Композитные рентгеновские карты распределения Са (a, черный цвет) и $\mathrm{Mg}$ (б, белый цвет) по сечению катионообменной мембраны МК-40 из приэлектродной секций реверсного электродиализатора (увеличение 100)

Снижение электропроводности и полной обменной емкости мембраны после эксплуатации в приэлектродной секции реверсного электродиализатора при обессоливании природных вод Аральского региона можно объяснить не только трансформацией функционального состава ионообменников, но и блокирующим эффектом вследствие иммобилизации осадка в фазу мембраны. В результате часть ионогенных групп переходит в связанное состояние и не принимает участие в ионном переносе, что приводит к увеличению электрического сопротивления системы. Снижение диффузионной проницаемости этих образцов подтверждает факт закупоривания транспортных каналов минеральными осадками.

\section{Заключение}

Таким образом, из возможных причин ухудшения эксплуатационных характеристик сульфокатионообменной мембраны МК-40 при электродиализе природных вод следует выделить деструкцию материала мембраны и образование на поверхности и в ее фазе малорастворимых соединений. Выявлены возможные механизмы снижения эксплуатационных характеристик сульфокатионообменной мембраны МК40 в процессе деминерализации природных вод методом электродиализа.

Причиной ухудшения транспортных свойств мембран является осадкообразование, затрагивающее не только поверхность, но и объем мембраны. Образование малорастворимых соединений приводит к блокировке функциональных групп и транспортных каналов мембран, уменьшает электропроводность и селективность, затрудняет диффузионные процессы.

Микрофотографии поверхности и объема мембран получены в ЦКПНО ВГУ. Работа выполнена при финансовой поддержке РФФИ (грант № 15-08-05031).

\section{Список литературы}

1. Уилсон Дж.Р. Деминерализация методом электродиализа. Москва, Госатомиздат, 1963. $351 \mathrm{c}$.
2. Korngold E., de Körösy F., Rahav R., Taboch M.F. // Desalination. 1970. Vol. 8. pp. 195-220. 
3. Кастючик А.С., Шапошник B.A. // Сорбиионные и хроматографические проuессы. 2009. Т. 9. № 1. С. 51-57.

4. Ивакина Е.И., Шаталов А.Я., Исаев Н.И. // Ионообменные мембраны в электродиализе. Ленинград, Химия, 1970, С. 78-84.

5. Бобрешова О.В., Лапшина Т.Е., Шаталов А.Я. // Журнал прикладной химии. 1980. Т. 53. № 3. С. 665-667.

6. Бобрешова О.В., Шаталов А.Я. // Журнал физической химии. 1977. Т. 51. № 1. С. 203-204.

7. Шапошник В.А., Зубец Н.Н., Стрыгина И.П., Милль Б.Е. // Журнал прикладной химии. 2001. Т. 74. № 10. С. 1604-1607.

8. Katz W.E. // Desalination. 1979. Vol. 28. pp. 31-40.

9. Гребенюк В.Д., Стрижак М.П. // Химия и технология воды. 1985. Т. 7. № 5. С. 39-40.

10. Пономарев М.И., Шендрик О.Р., Гребенюк В.Д., Антонов Ю.А. и др.// Химия и технология воды. 1989. Т. 11. № 1. С. 5860.

11. Mikhaylin S., Nikonenko V., Pourcelly G., Bazinet L. // Journal of Membrane Science. 2014. Vol. 468. pp. 389-399.

12. Гребенюк В.Д. Электродиализ. Киев. Техніка. 1976. $160 \mathrm{c}$

13. Lopatkova G., Basova O., Volodina E., Pismenskaya N. et al. // «Environmental Problems and Ecological Safety», Proceedings of the International Workshop, September - October 2004, Germany, pp. 145-153.

14. Салдадзе Г.К. // Ионселективные мембраны и электромембранные проиессы. М. НИИТЭХим, 1986, с. 18-24.

15. Березина Н.П., Ивина О.П., Рубинина Д.В. Диагностика ионообменных мембран после реального электродиализа. Краснодар, Изд-во Кубанского гос. ун-та. 1990. 11 с.

16. Салдадзе К.М., Климова 3.В., Титова Н.А., Базикова Г.Д. // Ионообменные мем-

\section{References}

1. Uilson Dzh.R. Demineralizatsiya metodom elektrodializa. M., Gosatomizdat, 1963, $351 \mathrm{p}$.

2. Korngold E., de Körösy F., Rahav R., Taboch M.F., Desalination, 1970, Vol. 8, pp. 195-220. DOI: Available at: браны в электродиализе. Ленинград, Химия, 1970. C. 65-75.

17. Письменская Н.Д., Никоненко В.В., Мельник Н.А., Шевцова К.А. // Мембраны и мембранные технологии. 2011. Т. 1. № 3. С. 201-212.

18. Васильева В.И., Акберова Э.М., Жильцова А.В., Черных Е.И. и др. // Поверхность. Рентгеновские, синхротронные и нейтронные исследования. 2013. № 9. С. 2734.

19. Акберова Э.М., Малыхин М.Д. // Сорбиионные и хроматографические проиессы. 2014. T. 14. № 2. С. 232-239.

20. Васильева В.И., Письменская Н.Д., Акберова Э.М., Небавская К.А. // Журнал физической химии. 2014. Т. 88. № 8. С. 11141120 .

21. Васильева В.И., Акберова Э.М., Шапошник В.А., Малыхин М.Д. // Электрохимия. 2014. Т. 50. № 8. С. 875-883.

22. Васильева В.И., Кранина Н.А., Малыхин М.Д., Акберова Э.М., Жильцова А.В. // Поверхность. Рентгеновские, синхротронные и нейтронные исследования. 2013. № 2. C. 51-61.

23. Березина Н.П., Кононенко Н.А., Дворкина Г.А., Шельшедов Н.В. Физикохимические свойства ионообменных материалов. Краснодар, Кубанский государственный университет, 1999, 82 с.

24. Berezina N.P., Kononenko N.A., Dyomina O.A., Gnusin N.P. // Advances in Colloid and Interface Science. 2008. Vol. 139, pp. 3-28.

25. Шапошник В.А., Емельянов Д.Е., Дробышева И.В. // Коллоидный журнал. 1984. Т. 46. № 4. С. 820-822.

26. Лурье Ю.Ю. Справочник по аналитической химии. М. Альянс. 1989. 446 с.

27. Гнусин Н.П., Гребенюк В.Д., Певницкая М.В. Электрохимия ионитов. Новосибирск. Наука. 1972. 200 с.

28. Nagaaki T. // Journal of the Chemical Society of Japan. 1973. No 3. p. 482.

http://www.sciencedirect.com/science/article/pii /S0011916400802301 (accessed 24.02.2017)

3. Kastyuchik A.S., Shaposhnik V.A., Sorbtsionnyye i khromatograficheskiye protsessy, 2009, Vol. 9, No 1, pp. 51-57. 
4. Ivakina E.I., Shatalov A.Ya., Isayev N.I, Ionoobmennyye membrany v elektrodialize. Leningrad, Khimiya, 1970, pp. 78-84.

5. Bobreshova O.V., Lapshina T.E., Shatalov A.Ya., Zhurnal prikladnoy khimii, 1980, Vol. 53, No 3, pp. 665-667.

6. Bobreshova O.V., Shatalov A.Ya., Zhurnal fizicheskoy khimii, 1977, Vol. 51, No 1, pp. 203-204.

7. Shaposhnik V.A., Zubets N.N., Strygina I.P., Mill' B.E., Russ. J. Applied Chem., 2001, Vol. 74, No. 10, pp. 1653-1657. DOI: Available at:

http://link.springer.com/article/10.1023/A\%3A1 014896916981 (accessed 24.02.2017)

8. Katz W.E., Desalination. 1979. Vol. 28, pp. 31-40. DOI: Available at: http://www.sciencedirect.com/science/article/pii /S0011916400881242 (accessed 24.02.2017)

9. Grebenyuk V.D., Strizhak M.P., Khimiya i tekhnologiya vody, 1985, Vol. 7, No 5, pp. 39-40.

10. Ponomarev M.I., Shendrik O.R., Grebenyuk V.D., Antonov YU.A. et al., Khimiya $i$ tekhnologiya vody, 1989, Vol. 11, No 1, pp. 5860.

11. Mikhaylin S., Nikonenko V., Pourcelly G., Bazinet L., J. of Membrane Science, 2014, Vol. 468, pp. 389-399. DOI: Available at: http:/www.sciencedirect.com/science/article/pii /S0376738814004219 (accessed 24.02.2017)

12. Grebenyuk V.D. Elektrodializ. Kiev, Tekhnika, 1976, 160 p.

13. Lopatkova G., Basova O., Volodina E., Pismenskaya N. et al., "Environmental Problems and Ecological Safety", Proceedings of the International Workshop, September - October 2004, Germany, pp. 145-153.

14. Saldadze G.K., Ionselektivnyye membrany $i$ elektromembrannyye protsessy. Leningrad, NIITEKhim, 1970, pp. 18-24.

15. Berezina N.P., Ivina O.P., Rubinina D.V. Diagnostika ionoobmennykh membran posle real'nogo elektrodializa, Krasnodar, $\mathrm{Ku}$ ban. Gos. Univ. Publ., 1990, 11 p.

16. Saldadze K.M., Klimova S.V., Titova N.A., Bazikova G.D., Ionoobmennyye membra$n y$ v elektrodialize. Leningrad, Khimiya, 1970, pp. 65-75.

17. Pis'menskaya N.D., Nikonenko V.V., Mel'nik N.A., Shevtsova K.A., Membrany $i$ membrannyye tekhnologii, 2011, Vol. 1, No 3, pp. 201-212.

18. Vasil'eva V.I., Akberova E.M., Zhiltsova A.V., Chernykh E.I. et al., J. of Surface Investigation. X-ray, Synchrotron and Neutron Techniques, 2013, Vol. 7, No 5, pp. 833-840. DOI: Available at: http://link.springer.com/article/10.1134/S10274 51013050194 (accessed 24.02.2017)

19. Akberova E.M., Malykhin M.D., Sorbtsionnyye i khromatograficheskiye protsessy, 2014, Vol. 14, No 2, pp. 232-239.

20. Vasil'eva V.I., Pismenskaya N.D., Akberova E.M., Nebavskaya K.A., Russ. J. Phys. Chem. A, 2014, Vol. 88, No 8, pp. 1293-1299. DOI: Available at: http://link.springer.com/article/10.1134/S00360 24414080317 (accessed 24.02.2017)

21. Vasil'eva V.I., Akberova E.M., Shaposhnik V.A., Malykhin M.D., Russ. J. Electrochem, 2014, Vol. 50, pp. 789-797. DOI: Available

at: http://link.springer.com/article/10.1134/S10231 9351408014X (accessed 24.02.2017)

22. Vasil'eva V.I., Kranina N.A., Malykhin M.D., Akberova E.M. et al., J. of Surface Investigation. X-ray, Synchrotron and Neutron Techniques, 2013, Vol. 7, No 1, pp. 144-153. DOI: Available at: http://link.springer.com/article/10.1134/S10274 51013010321 (accessed 24.02.2017)

23. Berezina N.P., Kononenko N.A., Dvorkina G.A., Shel'shedov N.V. Fizikokhimicheskiye svoystva ionoobmennykh materialov. Krasnodar, Kuban. Gos. Univ. Publ., 1999, 82 p.

24. Berezina N.P., Kononenko N.A., Dyomina O.A., Gnusin N.P., Advances in Colloid and Interface Science, 2008, Vol. 139, pp. 3-28. DOI: Available at: http:/www.sciencedirect.com/science/article/pii /S0001868608000286 (accessed 24.02.2017)

25. Shaposhnik V.A., Yemel'yanov D.Ye., Drobysheva I.V., Kolloidnyy zhurnal, 1984, Vol. 46, No 4, pp. 820-822.

26. Lur'ye Yu.Yu. Spravochnik po analiticheskoy khimii. Moscow, Al'yans, 1989, 446 p.

27. Gnusin N.P., Grebenyuk V.D., Pevnitskaya M.V. Elektrokhimiya ionitov. Novosibirsk, Nauka, 1972, 200 p.

28. Nagaaki T., Journal of the Chemical Society of Japan, 1973, No 3, p. 482. 
Яцев Андрей Михайлович - магистрант химического факультета, Воронежский государственный университет, Воронеж

Акберова Эльмара Маликовна - к.Х.н., ведущий инженер кафедры аналитической химии, Воронежский государственный университет, Воронеж.

Голева Елена Алексеевна - старший лаборант кафедры аналитической химии, Воронежский государственный университет, Воронеж

Васильева Вера Ивановна - д.Х.н., професcop кафедры аналитической химии, Воронежский государственный университет, Воронеж

Малыхин Михаил Дмитриевич - к.х.н., ведущий инженер кафедры аналитической химии, Воронежский государственный университет, Воронеж
Yatsev Andrey M. - the competitor for science degree of Master Science in Chemistry of the Analytical Chemistry Department, Voronezh State University, Voronezh, e-mail: yatsevandrey@mail.ru

Akberova Elmara M. - PhD (Chem.), leading engineer of the Analytical Chemistry Department, Voronezh State University, Voronezh, e-mail: elmara_09@inbox.ru.

Goleva Elena A. - senior assistant of the Analytical Chemistry Department, Voronezh State University, Voronezh

Vasil'eva Vera I. - Dr. Sci. (Chem.), the professor of the Analytical Chemistry Department, Voronezh State University, Voronezh, e-mail: viv155@mail.ru

Malykhin Mikhail D. - PhD (Chem.), leading engineer of the Analytical Chemistry Department, Voronezh State University, Voronezh 